\title{
The Uneven Diffusion of Collaborative Technology in a Large Organization
}

\author{
Gasparas Jarulaitis \\ Department of Computer and Information Science, \\ Norwegian University of Science and Technology, \\ Trondheim, Norway
}

\begin{abstract}
This paper investigates the large-scale diffusion of a collaborative technology in a range of different business contexts. The empirical data used in the article were obtained from a longitudinal (2007-2009) case study of a global oil and gas company (OGC). Our study reports on ongoing efforts to deploy an integrated collaborative system that uses Microsoft SharePoint (MSP) technology. We assess MSP as a configurational technology and analyze the diffusion of a metadata standard developed in-house, which forms an embedded component of MSP. We focus on two different organizational contexts, namely research and development (R\&D) and oil and gas production (OGP), and illustrate the key differences between the ways in which configurational technology is managed and used in these contexts, which results in an uneven diffusion. In contrast with previous studies, we unravel the organizational and technological complexity involved, and thus empirically illustrate the flexibility of large-scale technology and show how the trajectories of the various components are influenced by multiple modes of ordering.
\end{abstract}

Keywords: Uneven diffusion, multi-sited study, large-scale collaborative technologies, integration.

\section{Introduction}

The nature of diffusion of large-scale technologies is different from that of the diffusion of self-contained artefacts (i.e., products). A critical mass must be reached in order to diffuse a product successfully, and over time the diffusion of a product stabilizes. In contrast, large-scale technologies are not self-contained artefacts, and their attractiveness (and thus their diffusion) depends on whether or not the technology becomes integrated with other existing technologies. The more users become engaged with a system, the more complementary products are attracted to it, and the diffusion of large-scale technologies may thus be described by reinforcement mechanisms (Hanseth 2000). Because the diffusion of large-scale technologies, such as enterprise resource planning (ERP), customer relationship management (CRM), or the collaborative technologies is becoming more widespread (Pollock and Williams 2009), the discussion of why, how and with what consequences such technologies diffuse is becoming more intense. 
A number of studies have identified some of the challenges entailed in diffusing such technologies. According to Davenport (1998), the diffusion of such technologies inevitably entails some form of change, either organisational or technological, or a combination of both. Large-scale technologies have been described as being standardised and rigid, and as being responsible for imposing certain logical structures on established work practices. As a result, in order to put such technologies to work, appropriations (i.e., workarounds) by individual users must be carried out (Soh et al. 2000). In short, such technologies do not diffuse in the same way as stable artefacts; instead, they are continually modified during their diffusion.

In contrast to the view of large-scale technologies as being rigid and resistant to change, Fleck (1994) proposed that such technologies may be better understood as being configurational, consisting of multiple components that can be modified, removed, or added. Such technologies then provide a spectrum of various adjustment strategies (Pollock and Williams 2009, pp. 42-43). However, few studies have analysed large-scale technologies along these lines (but see de Laet and Mol 2000). We thus argue that there are few studies that unravel both the organisational and technological complexities involved and empirically illustrate the flexibility of largescale technologies and show how the trajectory of the various components is influenced by multiple modes of ordering (Law 1994).

The main aim of this paper is to explore the large-scale diffusion of technology across a range of contexts. The empirical data used in our paper are obtained from a longitudinal (2007-2009) case study of a global oil and gas company (OGC, a pseudonym to maintain anonymity). Our study reports ongoing efforts to deploy an integrated collaborative system based on Microsoft SharePoint (MSP). We assess MSP as a configurational technology and analyze the diffusion of a metadata standard, an embedded component that was developed in-house. We focus on two different organizational contexts, namely research and development (R\&D) and oil and gas production (OGP), and illustrate the various ways in which configurational technology is managed and used in different contexts, resulting in an uneven diffusion.

The remainder of this paper is organized as follows. In the next section, we conceptualize the diffusion of large-scale collaborative technologies. We then outline our research approach, introduce the historical context, and describe the intention of OGC to change its collaborative infrastructure. Thereafter, we illustrate and discuss the ways in which configurational technology is diffusing unevenly in different contexts. Finally, we provide some analytical and practical implications for the study and management of the diffusion of large-scale configurational technologies.

\section{Conceptualizing the Diffusion of Large-Scale Collaborative Technologies}

The transfer and diffusion of information technology is currently conceptualized in two distinct ways, namely as a product or as a process (Baskerville and Pries-Heje 2003). While the former conceptualization considers diffusion in a rather mechanical manner, the latter emphasizes the continuous effort required to sustain the diffusion. Studies of the process of diffusion often draw on process theories such as the actornetwork-theory or Walsham's interpretive framework (Henriksen and Kautz 2006). Our study builds on the latter perspective. 
The ways in which collaborative technologies are diffused in various settings is an important topic that is discussed widely in the computer-supported cooperative work (CSCW) literature (Munkvold 2003). Ciborra (1996) suggested that collaborative technologies are fragile and that when they fail, users tend to switch to other alternative media nearby. Indeed, the core findings of the CSCW suggest that "users appear to use groupware in another way than the groupware designers intended or IT departments expected. Users tend to 're-invent' the technology by developing novel uses" (Andriessen et al. 2003, p. 367). Collaborative technologies are not single-user applications and their primary function is to improve collaboration between and within groups. As a result, collaborative work should be based on an agreed set of rules for interaction (Mark 2002). At the same time, groupware systems should be flexible and should "encourage unanticipated and innovative patterns of use" (Andriessen et al. 2003, p. 367).

Lyytinen and Damsgaard (2001) argued that the diffusion of large-scale technologies is somewhat different to the process described above. Large-scale technologies consist of multiple interconnected components, which may also be reconfigured by adding or removing particular components. In short, such technology is not self-contained. The diffusion of large-scale technology is not determined by gaining a critical mass of users and reaching a saturation point, but rather by the continual improvement of the technology by adding and improving individual components. In that sense, "diffusion of innovation results from a series of innovations" (Baskerville and Pries-Heje 2003, p. 252).

Diffusion is unpredictable and does not occur automatically (Monteiro and Heps $\varnothing$ 1998). More importantly, diffusion is not complete when a particular technology is implemented and all the users trained. Technologies must be continually (re)enacted in local contexts(Orlikowski 2000). According to Fleck (1994), such a process is better described as innofusion, indicating that significant innovation takes place during its implementation. Local improvisations are required for the technology to diffuse: "without successful adaptation of particular components, no innovative configuration can result and no diffusion takes place" (Fleck 1994, p. 649).

The diffusion of large-scale technologies is not accomplished by a single centralized IT department, but requires a rather more distributed effort. As suggested by Law (1994), an organization does not follow a single system of logic, but its development is instead determined by multiple modes of ordering. According to Law, ordering is a continuous process, with multiple ordering activities running in parallel and interacting.

The way in which the same or similar technologies are diffused (i.e., implemented and used) within various different kinds of organizations is recognized to be an important research area within the field of Information Systems. A number of authors have acknowledged the situated nature of information systems (Orlikowski 2000) and have discussed various misfits (Soh et al. 2000) that occur when technology cuts across divergent contexts. Robey and Boudreau (1999) employed the logic of opposition and argued that either the same or similar technologies produce different outcomes both within the same organization or between different organizations. While exact workarounds (i.e., local appropriations) vary between contexts, largescale technologies do possess similarities (Leonardi and Barley 2008), because their diffusion processes are themselves similar. 


\section{Method}

We report on an ongoing longitudinal research project that began in January 2007. Our research approach can be thought of as an interpretive case study (Walsham 2006) because of our "attempts to understand phenomena through the meanings that people assign to them" (Klein and Myers 1999, p. 69).

Data collection began in early 2007 and had the primary aim of exploring the nature of the changes associated with the implementation of MSP technology. The study was multi-contextual, and aimed at analyzing the ways in which a collaborative technology diffuses in a variety of contexts. Two different business units of the same organization were studied. One of them was $R \& D$, where we engaged in conversations with various engineers working in technology development, and other researchers who were studying organizational issues. The second was OGP, where we aimed to cover the various disciplines involved in oil and gas production activities.

We employed three modes of data gathering, namely the use of formal and informal interviews, observation, and the use of documentary evidence. In total, 64 in-depth formal interviews, each lasting between 1 and 3 hours, were conducted. The first interviews were open-ended and aimed to identify the strategic IT visions and implementation activities related to MSP. During later interviews, we analyzed specific infrastructural components, work practices, or individual engagements with technology. The technological complexity and purpose of new infrastructure were discussed with developers, administrators, and managers of the collaborative infrastructure. We conducted 14 formal interviews with actors in this group. The use of collaborative infrastructure was explored with actors from several organizational units. A total of 23 formal interviews were conducted with various engineers and senior researchers in the R\&D department; 27 interviews were conducted with personnel in OGP, where we interviewed drilling, well, production, and process engineers.

Participatory observation and informal discussions were mainly carried out in one of the OGC research centers, to which the author had been granted access from the beginning of the data collection period. In January 2008, the author was granted office space, as well as access to the building and to the OGC IT network. A researcher then spent two or three days per week in the research center. The significant amount of time spent on site helped to form an understanding of how work was carried out in practice and the nature of the problems and frustrations that were experienced. In addition, being on site afforded the opportunity for informal but informative chats around a coffee machine or during lunch breaks.

The third major empirical source of data were the internal OGC documents. We carried out an extensive study of the strategic documents that related to the planning and implementation activities of MSP. In addition, we analyzed the technical descriptions, formal presentations and training materials of various infrastructural components. A number of policy documents, which defined how particular technology should be used or how specific work should be carried out, were studied in detail. Finally, OGC's intranet portal provided extensive contextual information on the diverse activities of OGC.

The data analysis procedures are ongoing and iterative. In our faculty, there are several actors (not only the author of this paper) who are currently exploring the ways 
in which collaborative technologies are used in OGC. We often meet and discuss. A significant part of the data analysis and validation process is in fact occurring with the help of OGC employees. During both informal and formal meetings, we frequently present our findings to various OGC employees. We are then challenged, supported, or directed to issues that require our further attention. For example, several record information managers (RIMs) supported our early findings on the use of metadata in R\&D, but we received extensive comments and suggestions for the study of other organizational contexts. We made adjustments to some of our generalizations. More importantly, we began to study the implementation of MSP in OGP.

In general, the empirical data are classified into broad themes that reflect a specific organizational project, practice, or technical component. Such a classification is neither all-encompassing nor exhaustive; it is rather characterized by overlapping and continual change. Theoretical considerations have an important role to play in the analysis by providing an analytical means to order and reclassify the empirical data. For example, in this paper we have analyzed the differences and similarities (Leonardi and Barley 2008) between different contexts. Our analysis is also inspired by STS studies, which emphasize multiplicities (Law 1994).

\section{Case Study}

\subsection{Oil and Gas Company}

Established in the 1970s, OGC has grown from a small, regional operator in northern Europe to a significant energy company, currently employing some 30,000 people with activities in about 40 countries across four continents. OGC has grown largely organically, but also by means of a few important national and international acquisitions. Facing limited growth potential in its region of origin, OGC is now actively pursuing a strategy of global growth. In order to boost its financial capacity and flexibility, in the 1990s OGC diversified and expanded its shareholder ownership including becoming listed on the New York Stock Exchange.

Aside from its growth in size, geography, and business area, OGC has been engaged in a number of corporate initiatives in order to improve communication and collaboration. These initiatives have relied heavily on the use of information systems. The first comprehensive effort to establish a corporate, collaborative infrastructure in this regard took place in the early 1990s, at a time of recession in the oil industry, falling oil prices, and low dollar exchange rates. The centralization, standardization, and market orientation of IT services was the direct outcome of several projects whose primary aim was to solve the problems of fragmented and incompatible IT. The outcome of these standardization activities led to the establishment of a collaborative infrastructure that used Lotus Notes.

The Lotus Notes infrastructure has proved successful inasmuch as it has been widely used for a range of different purposes. A key vehicle for facilitating collaboration within projects in OGC has been the Lotus Notes Arena (hereafter Arena) databases for the collective storing and dissemination of documents. However, the main challenge for this infrastructure has been to promote communication across the project-defined boundaries of the Arena databases. The Arena databases had no 
central indexing functionality, meaning that it was impossible to retrieve a document by searching if one did not know which database to search. With the existence of Arena databases that were thriving, apparently out of control (there were estimated to be some 5,000 databases at the latest count), locating relevant information stored outside the immediate scope of one's own project was far from being a trivial matter. Each user also had access to both personal (F disk) and departmental (G disk) storage areas. In short, information was scattered and duplicated over many storage areas.

\subsection{New Collaborative Infrastructure}

In order to overcome the problems associated with Lotus Notes and to establish more effective means of collaboration, coordination, and experience transfer, in 2001 OGC formulated a new strategy. According to this strategy, although OGC already possessed a set of general collaborative tools, "these tools [were] poorly integrated" and "there [was] a particular need for better and more integrated coordination tools, better search functionality and improved possibilities for sharing information with external partners" (OGC strategy documents). Accounting regulations enacted in the aftermath of the Enron affair increased the pressure to ensure a more systematic and consistent documentation of business decisions to better inform the stock market and the public at large.

The selection of the technology that would support the new collaborative strategy followed a long, rigorous process. A feasibility study was carried out in late 2002 . During 2003, several solution scenarios were developed, requirements specified, and vendors selected. In December 2003, a contract with a vendor was signed and at the beginning of 2004 , the first pilot using an $\mathrm{MSP}^{1}$ out-of-the-box solution was launched. Early experiences of this technology evoked multiple user requests for improvements. In addition, numerous technical components had to be developed in order to achieve better integration between MSP and the existing installed base systems. By the end of 2004, version 1.0 was released, but even so multiple improvements were again required.

The beginning of 2005 saw the release of version 1.1 and, as one manager explained, "we were ready to roll-out the solution." The role-out process was fairly fast, and by the end of October 2005 the final 5,000 users had been added. The technical part of the diffusion (i.e., adding some 25,000 users to the new system) was thus to a large extent problem-free and took less than a year.

MSP is a core element of OGC's new collaborative infrastructure. The central element of MSP is the so-called Team Site (TS), the virtual area for collaboration. TS provides the functionality for checking-in and checking-out documents, posting announcements, sharing links, and creating discussion boards. While MSP is mainly used for the management of documents, the technology is integrated with a corporatewide search engine, an archive system, and MS Exchange. The technology itself (MSP) is customizable; however, the OGC decided to make the solution as generic as possible so that it would fit all contexts (internally it is referred to as a one-size-fits-all strategy). As a result, all TSs have a common interface and functionality.

\footnotetext{
${ }^{1}$ http://sharepoint.microsoft.com/Pages/Default.aspx
} 


\subsection{Developing a Custom Component: The Metadata Standard}

According to IT managers, MSP was rather an immature solution and needed to be customized to comply with OGC's regulations. During pilot testing, it became apparent that MSP was unable to support complex folder hierarchies due to URL length limitations. The MSP implementation team also found it difficult to develop a common and controlled folder structure that would comply with corporate requirements. It implied that documents would be stored in TSs in a flat structure. In order to improve information retrieval and retention, the MSP implementation team decided to utilize the metadata of documents. Two options for metadata were defined, namely the automatic selection of metadata from documents and the implementation of a controlled vocabulary. The latter alternative was chosen. The metadata standard was collaboratively developed by the MSP project team, RIMs and process owners (PO). RIMs would define and maintain metadata structure and POs would primarily be responsible for developing the values of the metadata. The structure of the metadata standard was inspired by the Dublin Core Metadata Initiative ${ }^{2}$ (DCMI). DCMI defines a simple set of elements for describing document-like objects. OGC made significant customization and the current metadata structure has 13 elements with corresponding sub-elements (see Table 1). In total, there are fewer than 100 subelements. Our analysis primarily focuses on the activity and category sub-elements from the element subject. While some of the metadata values are captured automatically, such as the date or document format, others need to be defined and assigned manually. Category and activity sub-elements values are pre-defined by POs and users must assign each value as they create a new document in a TS (see Figure 1). The activity sub-element indicates a specific activity to which a document is related and the category sub-element is intended to describe the outcome of that activity.

Table 1. The Metadata Standard Structure

\begin{tabular}{|c|c|}
\hline 1. $\quad$ People and roles & 5. Description \\
\hline Rights management & 6. Language \\
\hline 3. Title & 7. $\quad$ Relation \\
\hline 4. $\quad$ Subject & 8. Coverage \\
\hline $4.1 \quad$ BICS 1 & 9. Date \\
\hline $4.2 \quad$ BICS 2 & 10. $\quad$ Status \\
\hline $4.3 \quad$ Category & 11. Format \\
\hline $4.4 \quad$ Activity & 12. Identifier \\
\hline $4.5 \quad$ Keyword & 13. Preservation history \\
\hline
\end{tabular}

Metadata values are stored in a so-called metadata repository, which is technically part of MSP; however, the metadata is utilized in the corporate-wide search engine and the archive system as well. In that sense, metadata is an integrated component of

${ }^{2}$ http://dublincore.org/ 
the collaborative infrastructure. As discussed previously, TS functionality and user interface are standardized for all users, thus the metadata is the only element that makes the TSs different. In contrast with Lotus Notes, MSP is configured to impose more standardization between geographical locations. Metadata value sets are standardized, which means, for example, that drilling engineers work with the same set of metadata irrespective of their geographical location or the specific characteristics of the particular oil and gas field. In that sense, the metadata standard not only provides a controlled vocabulary for the classification of documents, but also aims to improve the process of information retrieval. Since the metadata standard is integrated with the search engine, all users have the functionality required to search and filter information according to the metadata values.An implicit, but crucial, aspect of this functionality is that the same "common" metadata values be used in all contexts. In addition, the metadata standard may be considered as an initiative for improving the retrieval of long-term information and for ensuring compliance with external laws and regulations. ${ }^{3}$ The metadata standard is integrated with the corporate archive solution (i.e., the document is archived with its associated metadata and may be found later on using the search engine).

Both the current structure and values of the metadata standard are subject to continual change. RIMs explained it as a "fumbling start":

In the first release users had very few and too generic metadata values. The process of defining metadata was new to process owners...in some cases it took a couple years before more and better metadata values were developed.

The initial versions of the metadata standard were experienced as a top-down solution for users, because both the structure and the values were defined beforehand. Recently, a free text sub-element called keyword was added in order to provide greater flexibility. The metadata values are subject to continual change as well. Despite the common character of the metadata standard, the nature of the diffusion thus varies greatly between contexts.

\section{Analysis: How Does the Metadata Standard Diffuse in Different Contexts?}

In this section we analyze and compare the diffusion of the metadata standard between different contexts. Two distinct organizational units are compared: R\&D and OGP. The analysis highlights differences in the development of metadata and their patterns of use (see Table 2 for a summary).

\subsection{Metadata in R\&D: Developing Specific Values That Fit the Local Context}

$\mathrm{R} \& \mathrm{D}$ is an organizational unit that conducts research in special laboratories within the fields of materials technology, energy and environmental analysis, oil refining, gas

${ }^{3}$ Being listed on the New York Stock Exchange, OGC must comply with U.S. laws and regulations. The Sarbanes-Oxley act (SOX) of 2002 is a United States federal law enacted on July, 30, 2002, as a reaction to a number of major corporate and accounting scandals. The primary intention of SOX is to ensure the accuracy and transparency of financial statements. 
and oil processing, gas conversion and petrochemicals, and biotechnology. Other research covers softer issues including, for example, the analysis of work practices in order to improve collaboration. Some research projects are conducted in specific areas (like the one mentioned above), while in other cases research projects are innovative and may cut across a variety of disciplines. The "newness" of R\&D activities has implications for the development of metadata. It implies that a new set of metadata values should be developed whenever an innovative project is launched. The idea of the metadata values in OGC, on the other hand, was to engender a more static and less responsive process of change. Although the diffusion of MSP began in 2005, R\&D is not thought of as a valid business process and currently (i.e., mid 2009), metadata values have not been developed. During a formal interview in late 2008, a RIM explained that development is in progress and a group of people from R\&D are working on this in collaboration with process owners and RIMs. The core question then becomes one of how users are to classify documents without the use of metadata.

Some R\&D projects aim to develop specific technology that could improve reservoir modeling, drilling, or other core oil and gas production activities. In that sense, some metadata values can be borrowed from other processes:

Table 2. Comparison of Diffusion of the Metadata Standard between Contexts

\begin{tabular}{|c|c|}
\hline Research and Development & Oil and Gas Production \\
\hline \multicolumn{2}{|c|}{ Metadata development } \\
\hline $\begin{array}{l}\text { - Lagging development of metadata } \\
\text { values } \\
\text { - Non-engaged process owners }\end{array}$ & $\begin{array}{l}\text { - Active development and maintenance of } \\
\text { metadata values } \\
\text { - Active process owners and engaged users }\end{array}$ \\
\hline \multicolumn{2}{|c|}{ Metadata use patterns } \\
\hline $\begin{array}{l}\text { - Navigating by name or date } \\
\text { - Borrowing metadata values from other } \\
\text { processes } \\
\text { - Inevitable working-around (replacing } \\
\text { default values) } \\
\text { - Side-stepping MSP (using file-servers) }\end{array}$ & $\begin{array}{l}\text { - Inconsistent (or wrong) use of metadata } \\
\text { values } \\
\text { - Working-around (creating portals with } \\
\text { links to documents) } \\
\text { - Using sorting and filtering functionality }\end{array}$ \\
\hline
\end{tabular}

When we create a new team site, we have to define, which metadata we will use, but there is no metadata set for $R \& D$...so I choose from other processes, for instance "petroleum technology.” (Researcher).

Even where metadata values are borrowed from other processes, they are quite generic and do not reflect actual activities:

The project I am working on is quite local, some 10 engineers are located in this building....we meet once a week to discuss the status of the project and plan the work ahead. I do not use metadata since many values are very generic. I have a good overview of the project, I know who is working with what and when certain deliveries have to be produced... it is easy to find documents, most often I sort documents by name or by date. (Researcher)

OGC policy states that users should use the metadata values provided, however TS administrators are given the permissions required to change metadata values. While 
some use generic values, others question the rationale behind the use of generic values: "We cannot change values, but what is the reason for using values that are meaningless in the project?" (Researcher). Accordingly, some of them think that it is better to replace the metadata values provided rather than to use ones that do not fit. Figure 1, for example, illustrates the use of a TS with replaced values. Initially, the TS contained such generic values as accounting and control, best practice, manage coordination, network and competence, target setting and planning, experience and lessons learned, external document, publication, and report. The project team did not see the reason for using such values, and replaced them with ones that reflected actual activities (i.e., video, Canada, and needs).

\section{Document Library}

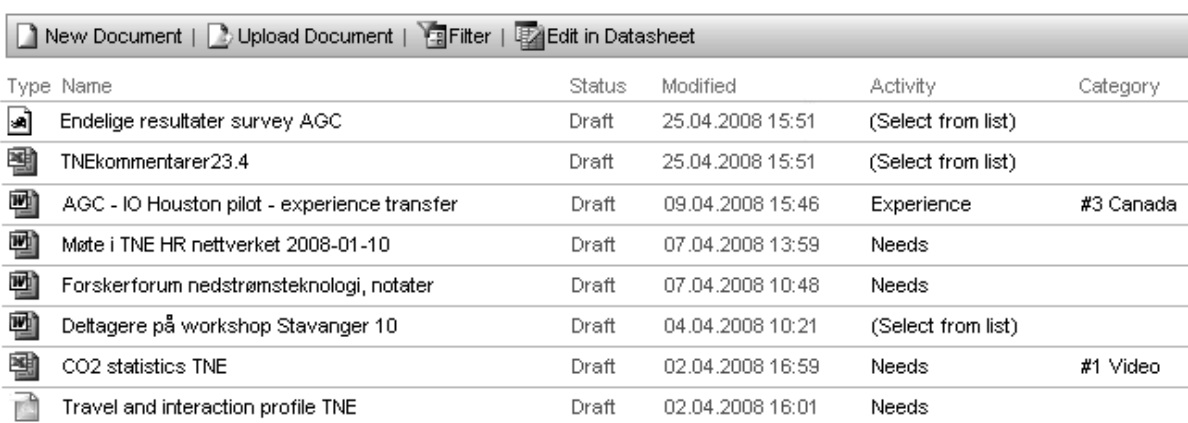

Fig. 1. Use of Metadata Values in R\&D

We have observed many users during our research, and many of them know, or get to know, that changing metadata values quite often allows such a workaround. One engineer's expression illustrates the situation well: "Someone recently told me that it is possible to change values... it is much better now."

In some extreme cases, our respondents knew nothing or very little about the metadata:

We are working in laboratories with some specialized systems. Some files are very large and some formats are not actually supported by MSP. So it is much easier for us to use file servers with common folders. We have TSs in parallel, but most of the things [i.e., files] are not there. (Researcher)

As explained by a RIM involved in R\&D activities, the greatest challenge occurs when $\mathrm{R} \& \mathrm{D}$ projects cut across multiple disciplines:

It is difficult to define what new and innovative projects there will be in the future. In particular, it is a big challenge when a single project cuts across multiple processes. I don't know in detail how it is in other places [other OGC organizational units], but here [in $R \& D$ ] it is difficult. (RIM). 


\subsection{Metadata in OGP: Learning How to Navigate in an Imperfect Information Space}

OGP is a distinct business unit within OGC. OGP may be characterized as an interdisciplinary, heterogeneous, and distributed work activity. The oil and gas value chain spans such activities as exploration, well drilling, and the optimization of production. The central object in OGP is a well. Geophysicists, petrophysicists, and drilling and reservoir engineers are all involved in the planning of new wells. While the drilling is primarily controlled by drilling engineers, production engineers observe well performance and initiate well interventions during production, which are then performed by well engineers. These activities are interdependent and distributed in time and space as the different disciplines work with the same well over a period of many years. Multiple specialist technologies are used to visualize well data and observe its performance. Other information related to planning and administration is stored using collaborative technologies such as MSP.

Metadata was introduced in OGP at the same time as in R\&D and other parts of the company. However, the development of metadata has received a greater level of attention in OGP than in other parts of the company. Several managers and users participated in the project to develop metadata values. The prioritization of the project may be explained by several factors. First, the activities of OGP generate a large number of documents; during well planning alone, several hundred documents can be produced. Second, OGP is a core OGC activity, where certain policies on document retention must be followed. Third, engineers, who are used to building abstractions, constitute the large majority of OGP workers. As one manager explained, "We [OGP] rather quickly understood that things would go wrong if we did nothing. So right from the beginning several managers and engineers started to work on metadata."

The comments made by the users in OGP are divergent, yet a majority have had positive experiences.

We [OGP] are quite good at classifying, because we have many values to choose from....The metadata does not actually fit all the documents, but for the large majority [of documents] values are good. (Drilling engineer)

Other engineers emphasize that fewer, but more precise. values would perhaps be easier to use.

The people who made this were very enthusiastic and thought that this would be a very good 'system' and specified as you can see many words [metadata values]. But when people begin to use this...if people don't know which value to use then they will use "none"...so it is important to have a rigid process with few words so it will be much easier for people to use it. (Engineer)

The navigation and organization of overwhelming numbers of documents in a single TS is time consuming and not always successful, and many engineers appreciate the ability to filter and sort documents in a variety of ways. In particular, predefined filters (so-called views), which allow the sorting of documents according to certain criteria, is considered to be a very helpful functionality (see Figure 2). 
The success of common classification implies that the different actors who use the classification have the same (or similar, but not different) interpretation of values and use them in a consistent manner. This is not always the case in OGP, however. Some documents are not classified, and some are classified incorrectly. In contrast to the R\&D example discussed in the previous section, it is quite rare in OGP to have a good overview of who is working with what.

\begin{tabular}{|c|c|}
\hline EXTRANET & Home Documents and Lists Site Settings Users Help \\
\hline & $\begin{array}{l}\text { Well Intervention } \\
\text { Document Library }\end{array}$ \\
\hline SELECT A VIEW & Documents managed by team. \\
\hline All Documents & New Document | [2 Upload Document | \\
\hline $\begin{array}{l}\text { My Recent } \\
\text { Documents }\end{array}$ & \& Modified By \\
\hline $\begin{array}{l}\text { Expired Documents } \\
\text { Created By }\end{array}$ & $\begin{array}{l}+ \text { Activity : (Select from list) }(19) \\
\text { — Activity : Administration }(9)\end{array}$ \\
\hline ActivityiCategory & $\begin{array}{l}+ \text { Category : Analysis / Simulation / Calculation (1) } \\
+ \text { Category : Background information (2) }\end{array}$ \\
\hline ActivityMellbore & \pm Category : Dispensation / Deviation (2) \\
\hline Wellbore/Activity & \pm Category : Experience and lesson learned (1) \\
\hline Business partner & † Category : Strategy and plan (1) \\
\hline $\begin{array}{l}\text { Barrier envelope } \\
\text { drawings }\end{array}$ & $\begin{array}{l}\text { † Activity : Plug and abandon (P\&A) } 1 \text { (5) } \\
\text { — Activity : Well intervention } 1 \text { (453) }\end{array}$ \\
\hline A.ll link pages & $\begin{array}{l}+ \text { Category : (50) } \\
+ \text { Category : Analysis / Simulation / Calculation (9) }\end{array}$ \\
\hline ACTIOIS & $\mp$ Category : As run detailed operational procedure $(4)$ \\
\hline$\square$ Create New View & $\mp$ Category : Background information (68) \\
\hline$\square$ Delete View & $\begin{array}{l}\text { + Category : Detailed operational procedure (36) } \\
\text { + Category : Experience and lesson learned }(13)\end{array}$ \\
\hline$\square$ Alert me & † Category : HSE documentation (10) \\
\hline $\begin{array}{l}\text { Gexport to } \\
\text { spreadsheet }\end{array}$ & $\begin{array}{l}+ \text { Category : Method selection }(33) \\
\text { + Category : Program }(149)\end{array}$ \\
\hline $\begin{array}{l}\text { 口. Modify settings and } \\
\text { columns }\end{array}$ & $\begin{array}{l}+ \text { Category : QA / QC follow up }(5) \\
+ \text { Category : Risk assessment }(50)\end{array}$ \\
\hline${ }^{\square}$ Bulk Declare & $\mp$ Category : Strategy and plan (1) \\
\hline \multirow[t]{3}{*}{ ๑View Fileplan } & \pm Category : Tally $(5)$ \\
\hline & — Activity : Well intervention 2 (195) \\
\hline & † Category: (43) \\
\hline
\end{tabular}

Fig. 2. The Filtering of Documents According to Multiple Criteria in OGP

It is great if you know who has produced or uploaded a specific document, but it is not always the case...If you use a specific team site a lot, then it is easier, because you know what to look for...but sometimes I just go and ask people where a specific document is. (Drilling engineer)

The difficulties of using metadata are especially acute for engineers working offshore, and thus onshore engineers have invented a way in which offshore engineers can sidestep the use of metadata. 
Sometimes I get a call in the evening from offshore people saying that they have been searching for a specific document for an hour or so with no success...to avoid this we have developed a practice [which is unofficial, i.e., a workaround] that for every new drilling program, a drilling engineer [working onshore] creates an Excel document containing links to documents that are the most important ones for drilling engineers working offshore. It is additional work as we [engineers working onshore] have to update those excel documents during drilling, but then offshore people have a much better overview. (Drilling engineer working onshore).

Engineers who are working on a range of different oil and gas fields are exposed to inconsistency and difficulty using the activity and category values.

The most important metadata for me is wellbore [well number, which is rather unambiguous], the rest has little value. The main thing I do is I sort documents according to a specific well [see Figure 2, top left corner] and then navigate... we [engineers conducting well interventions] also have internally decided document naming logic and agreed that all documents should start with a well number so that it would be easier to navigate. (Well engineer).

\section{Discussion and Conclusions}

Our discussion relates to how a large-scale technology diffuses across contexts. The core findings of different studies suggest that the use of the same or similar technology produces different results in different contexts. The different outcomes arise due to the openness of the technologies (in particular the collaborative ones) (Ciborra 1996), which are subsequently interpreted and enacted differently by the various groups of users (Orlikowski 2000). We contribute to this body of literature by providing some of the analytical and practical implications of this statement.

In contrast to studies of the diffusion of a particular technology as a whole, our study recognizes that large-scale systems are best conceptualized as configurational technologies (Fleck 1994). This conceptualization emphasizes the fact that the technology consists of multiple components rather than a fixed set of modules or functionalities. Configurational technologies are "built from a combination of standard and custom technology components from different suppliers, selected and adapted to the user's context and purposes" (Pollock and Williams 2009, p. 47).

Technology does not diffuse as a whole; instead multiple components are continually modified and subsequently appropriated in a variety of ways. MSP, then, is not a rigid and unchangeable technology, on the contrary, it is rather flexible and offers a spectrum of various configurations (Pollock and Williams 2009, pp. 42-43). MSP is a configurational technology and the metadata standard is an internally developed component aimed at improving information retrieval and retention. The metadata standard is an embedded component of MSP, which implies that the trajectory of the metadata standard is influenced by its interactions with other components. More importantly, the metadata standard also influences the trajectory of the collaborative infrastructure. For example, the structure and rigidity of the 
metadata standard was influenced by the fact that MSP could not support complex folder hierarchies. The incorrect classification of documents, on the other hand, makes it difficult or sometimes impossible to find documents using the corporatewide search engine.

While the concept of configurability was originally associated with the modification of technical parameters, recent contributions have extended this concept and illustrate how the politics of a small software supplier need to be configured according to changing circumstances (Sahay et al. 2009). Similarly, we suggest that successful configuration not only specifies technical parameters, but also involves multiple modes of ordering (Law 1994).

Since the technology consists of multiple components, it is quite often the case that certain communities are responsible for managing a particular component. In that sense, the diffusion of the same technology is a collective, yet distributed, effort. In the case of OGC, a certain community defines the overall strategy for the collaborative infrastructure but others have particular responsibility for the search engine, for document archiving, or for messaging services. The metadata standard is managed by several communities. RIMs maintain the structure and POs define the metadata values. In addition, there are multiple user communities, only a few of which we have illustrated herein. The core message then, is that the trajectory of either the metadata standard or MSP does not follow a single pathway; instead, multiple modes of ordering (Law 1994) continually apply. As illustrated for OGC, MSP had been technically rolled-out by the IT department by late 2005; however, tensions among communities are still present. RIMs, for example, are working closely with users, but their perspectives are not necessarily aligned with those of POs: "Even if the users and I [RIM] know which metadata values would work better in particular contexts, we should not change them, it is the POs' responsibility to define them. We can suggest values for improvements, but it will not necessarily happen" (RIM). Collaboration between POs and users is also quite problematic, especially in R\&D. Users are not involved in the process of defining metadata values, thus their dissatisfaction is not surprising. In short, it is not only the technical aspects that should be configurable, but so should the modes of ordering. In OGC, for example, we find that the POs represent a bottleneck in the current configuration.

The practical implications of this study relate to the management of configurational technologies. Our study shows how configurational technology diffuses unevenly, a finding that supports the process perspective of diffusion (Henriksen and Kautz 2006). It requires different amounts of work from users and managers across different organizational contexts to make the technology work. As result, the diffusion of the technology occurs at different rates. Configurational technologies are not single-user applications; instead, they aim to provide collective benefits and require similar management and use across different contexts. Our study shows how the different ways of managing the same component has significant unwanted consequences. The owners of the processes did not develop the metadata values for R\&D and, in consequence, some 1,000 engineers working in R\&D had to use TSs with inappropriate metadata. As a result, documents were archived using incorrect metadata. Investigating the activities of the $\mathrm{R} \& \mathrm{D}$ department over the last 5 years is rather difficult, either using a corporate-wide search engine or an archive. The successful 
retrieval of information, therefore, becomes dependent on personal networks rather than on IT tools.

Mark (2002) emphasized the fact that collective work should be guided by agreed rules of interaction. Our empirical case shows that it is important not only to understand how technology is used, but it is equally important to monitor whether technology is managed according to agreed rules. The use of configurational technology imposes certain challenges on managers. Such technologies do not have distinct stages of design and use. These stages are intertwined as continuous configurations are made over time. Thus, the gap between designer and user needs to be bridged continuously. The metadata standard in OGC is an example of one particular configuration. While RIMs defined the metadata structure, POs were neither familiar with the concept of metadata nor with the process of the development of metadata values. In addition, POs have many different responsibilities and work related to the improvement of metadata does not currently enjoy a high priority. Thus, the interests of RIMs and POs are not currently aligned. The practical implication of this, then, is that it is not sufficient to define guidelines for the management of use of a configurational technology. The continuous assessment and improvement of both management and use are required. In essence, configurational technology requires significant resources.

\section{Acknowledgments}

I would like to thank Eric Monteiro, Hans Hysing Olsen, and the anonymous reviewers for their very helpful comments during the revision of the paper. This research was supported by the AKSIO project, which is funded by the Norwegian Research Council (PETROMAKS, pr.nr. 163365/S30).

\section{References}

Andriessen, J.H.E., Hettinga, M., Wulf, V.: Introduction to Special Issue on Evolving Use of Groupware. Computer Supported Cooperative Work (CSCW) 12(4), 367-380 (2003)

Baskerville, R., Pries-Heje, J.: Diversity in Modeling Diffusion of Information Technology. Journal of Technology Transfer 28(3-4), 251-264 (2003)

Ciborra, C.U.: Groupware and Teamwork: Invisible Aid or Technical Hindrance? John Wiley, Chichester (1996)

Davenport, T.H.: Putting the Enterprise into the Enterprise System. Harvard Business Review 76(4), 121-131 (1998)

de Laet, M., Mol, A.: The Zimbabwe Bush Pump: Mechanics of a Fluid Technology. Social Studies of Science 30(2), 225-263 (2000)

Fleck, J.: Learning by Trying: The Implementation of Configurational Technology. Research Policy 23(6), 637-652 (1994)

Hanseth, O.: The Economics of Standards. From Control to Drift. In: Ciborra, C.U., Braa, K., Cordella, A., Dahlbom, B., Failla, A., Hanseth, O., Hepso, V., Ljungberg, J., Montrero, E. (eds.) The Dynamics of Corporate Information Infrastructures, pp. 56-71. Oxford University Press, Oxford (2000) 
Henriksen, H.Z., Kautz, K.: An Analysis of IFIP TC 8 WG 8.6 - In Search for a Common Theoretical Denominator. In: Avison, D., Elliot, S., Krogstie, J., Pries-Heje, J. (eds.) The Past and Future of Information Systems: 1976-2006 and Beyond, pp. 143-152. Springer, New York (2006)

Klein, H.K., Myers, M.D.: A Set of Principles for Conducting and Evaluating Interpretive Field

Studies in Information Systems. MIS Quarterly 23(1), 67-94 (1999)

Law, J.: Organizing Modernity. Blackwell, Oxford (1994)

Leonardi, P.M., Barley, S.R.: Materiality and Change: Challenges to Building Better Theory About Technology and Organizing. Information and Organization 18(3), 159-176 (2008)

Lyytinen, K., Damsgaard, J.: What's Wrong with the Diffusion of Innovation Theory? In: Ardis, M.A., Marcolin, B.L. (eds.) Proceedings of the IFIP TC8 WG8.1 Fourth Working Conference on Diffusing Software Products and Process Innovations, pp. 173-190. Kluwer, Boston (2001)

Mark, G.: Conventions and Commitments in Distributed CSCW Groups. Computer Supported Cooperative Work 11(3), 349-387 (2002)

Monteiro, E., Heps $\varnothing$, V.: Diffusion of Infrastructure: Mobilization and Improvisation. In: Larsen, T.J., Levine, L.L., DeGross, J.I. (eds.) Information Systems: Current Issues and Future Challenges, pp. 255-274. IFIP, Laxenburg (1998)

Munkvold, B.E.: Implementing Collaboration Technologies in Industry Case Examples and Lessons Learned. Springer, London (2003)

Orlikowski, W.J.: Using Technology and Constituting Structures: A Practice Lens for Studying Technology in Organizations. Organization Science 11(4), 404-428 (2000)

Pollock, N., Williams, R.: Software and Organizations: The Biography of the Enterprise-Wide System or How SAP Conquered the World. Routledge, London (2009)

Robey, D., Boudreau, M.-C.: Accounting for the Contradictory Organizational Consequences of Information Technology: Theoretical Directions and Methodological Implications. Information Systems Research 10(2), 167-185 (1999)

Sahay, S., Monteiro, E., Aanestad, M.: Configurable Politics and Asymmetric Integration: Health e-Infrastructures in India. Journal of the Association for Information Systems 10(5), 399-414 (2009)

Soh, C., Kien, S.S., Yap, T.J.: Cultural Fits and Misfits: Is ERP a Universal Solution? Communications of the ACM 43(4), 47-51 (2000)

Walsham, G.: Doing Interpretive Research. European Journal of Information Systems 15(3), 320-330 (2006)

\section{About the Author}

Gasparas Jarulaitis is a research fellow in the Department of Computer and Information Science at the Norwegian University of Science and Technology. His research interests focus on the implementation and use of large-scale information systems in organizations. He has published in the proceedings of international IS conferences. Gasparas can be reached at gasparas@idi.ntnu.no. 